\title{
High sensitivity C-reactive protein in asthma
}

\author{
M. Takemura*, H. Matsumoto*, A. Niimi*, T. Ueda*, H. Matsuoka*, M. Yamaguchi*, \\ M. Jinnai*, S. Muro*, T. Hirai*, Y. Ito*, T. Nakamura*, T. Mio*, \\ K. Chin ${ }^{\#}$ and M. Mishima*
}

ABSTRACT: Asthma is characterised by chronic inflammation of the airways, but the relevance of high-sensitivity assays for C-reactive protein (hs-CRP), which are known to be a sensitive marker of low-grade systemic inflammation, has not been fully studied in asthma. The objective was to examine serum hs-CRP levels in patients with asthma and their relationship to clinical characteristics and degree of airway inflammation.

Serum hs-CRP levels were cross-sectionally examined in steroid-naive $(n=22)$ and steroidinhaling $(n=23)$ adult patients with asthma and healthy controls $(n=14)$. All were nonsmokers.

Serum hs-CRP levels were significantly increased in steroid-naive patients (mean \pm SD $\left.1.33 \pm 1.48 \mathrm{mg} \cdot \mathrm{L}^{-1}\right)$ compared with controls $\left(0.21 \pm 0.30 \mathrm{mg} \cdot \mathrm{L}^{-1}\right)$, but not in patients on inhaled corticosteroid. Among steroid-naive patients, serum hs-CRP levels significantly negatively correlated with indices of pulmonary function (forced expiratory volume in one second/forced vital capacity and forced mid-expiratory flow) and positively with sputum eosinophil count. Among patients on inhaled corticosteroid, hs-CRP levels did not correlate with any indices.

In conclusion, an increase in serum C-reactive protein levels measured by high-sensitivity assays may be associated with airflow obstruction and airway inflammation, and may serve as a surrogate marker of airway inflammation in asthma.

KEYWORDS: Airway inflammation, asthma, high-sensitivity C-reactive protein, induced sputum

0 erum levels of the well-known inflammatory marker C-reactive protein (CRP) can be simply and inexpensively measured in order to assess systemic inflammation [1]. However, standard assays for CRP, with a lower detection limit of 3-8 $\mathrm{mg} \cdot \mathrm{L}^{-1}$, lack the sensitivity required to determine levels of inflammation within the normal range [2]. Recently, highsensitivity assays for CRP (hs-CRP) have become available in clinical laboratories. Measurement of serum hs-CRP levels has suggested the involvement of low-grade systemic inflammation in several disorders, such as cardiovascular disease and diabetes mellitus [3-6]. Serum hs-CRP levels can be a prognostic marker for the development of diabetes mellitus [7] or future cardiovascular events $[8,9]$. Furthermore, a recent populationbased study showed associations of increased levels of serum hs-CRP with a high frequency of airway hyperresponsiveness and low forced expiratory volume in one second (FEV1) among subjects without heart disease [10], suggesting that systemic inflammation may be associated with respiratory impairment. Another recent epidemiological study showed that elevated levels of hs-CRP correlate significantly with

For Editorial comments see pages 874 and 877 . respiratory symptoms and with prevalence of nonallergic asthma [11].

Asthma is characterised by airway hyperresponsiveness and inflammation, in which various cells (such as eosinophils, neutrophils, macrophages and T-lymphocytes), cytokines and mediators play a role. Beside local inflammation, systemic inflammation is present in asthma, as shown by increased levels of plasma fibrinogen and serum amyloid A [12]. Thus hs-CRP could theoretically also be a useful tool for detecting systemic inflammation in asthma; indeed, an association between serum hs-CRP level and severity of asthma has been suggested [13]. However, correlation between serum hs-CRP levels and airway inflammation in asthma has not been examined to date.

In the present study, the serum levels of hs-CRP of asthmatic patients with and without inhaled corticosteroid (ICS) treatment were compared with those of healthy controls. The relationship of serum hs-CRP levels to clinical indices and inflammatory cell differentials were then investigated in induced sputum.

\section{METHODS}

Study population and design

Healthy controls $(n=14)$ and two groups of adult patients with asthma diagnosed according to

\section{AFFILIATIONS}

Depts of *Respiratory Medicine, and \#Physiotherapy, Graduate School of Medicine, Kyoto University, Kyoto, Japan.

CORRESPONDENCE

H. Matsumoto

Dept of Respiratory Medicine

Postgraduate School of Medicine Kyoto University

Sakyo-ku

Kyoto 606-8507

Japan

Fax: 81757514643

E-mail: hmatsumo@kuhp.

kyoto-u.ac.jp

Received:

October 022005

Accepted after revision:

November 252005 
American Thoracic Society criteria [14], 23 patients receiving ICS $\left(967 \pm 372 \mu \mathrm{g} \cdot\right.$ day $^{-1}$ expressed as the equivalent dose of CFC-beclomethasone dipropionate) (ICS+ group) and 22 steroid-naive patients treated with short-acting inhaled $\beta_{2^{-}}$ agonists as required (ICS- group), were cross-sectionally studied. None of the subjects was a smoker or had a respiratory tract infection or exacerbation of asthma during the month before enrolment. Subjects with heart disease, diabetes mellitus, cancer status, obesity (body mass index $(\mathrm{BMI}) \geqslant 30 \mathrm{~kg} \cdot \mathrm{m}^{-2}$ ) and systemic inflammatory disorders (such as collagen vascular diseases) were excluded clinically and serologically. Subjects whose serum CRP levels by standard assay were $>10 \mathrm{mg} \cdot \mathrm{L}^{-1}$ were excluded. This study was approved by the Ethics Committee of the Graduate School of Medicine (Kyoto University, Kyoto, Japan) and written informed consent was obtained from all participants.

\section{Sputum induction and processing}

Sputum induction and processing were performed as described by PIN et al. [15], with slight modification [16]. Briefly, subjects were premedicated with inhaled salbutamol $(200 \mu \mathrm{g})$, and inhaled hypertonic $(3 \%)$ saline solution, administered for $15 \mathrm{~min}$ from an ultrasonic nebuliser (MU-32; Azwell, Inc., Osaka, Japan). Subjects were then asked to try to cough sputum into a plastic Petri dish. All adequate plugs of sputum were separated from saliva and treated with $0.1 \%$ dithiothreitol (Sputasol ${ }^{\mathrm{TM}}$; Oxoid Ltd, Basingstoke, UK) followed by Dulbecco's PBS. After centrifugation, differential cell counts were determined by counting $\geqslant 400$ nonsquamous cells in specimens stained using the May-Grünwald-Giemsa method.

\section{Measurement of serum high-sensitivity C-reactive protein levels}

Samples of peripheral venous blood were collected and centrifuged for $10 \mathrm{~min}$ at $1,300 \times g$ at $4^{\circ} \mathrm{C}$. The sera were stored at $-20^{\circ} \mathrm{C}$. Serum hs-CRP levels were measured using a highly sensitive CRP assay (Behring Latex-Enhanced using the Behring Nephelometer BN-100; Behring Diagnostics, Westwood, MA, USA). The sensitivity of the assay ranged $0.04-5.0 \mathrm{mg} \cdot \mathrm{L}^{-1}$.

\section{Pulmonary function}

Pre-bronchodilatory FEV1, FEV1/forced vital capacity (FVC) and forced mid-expiratory flow (FEF25-75\%) were measured using a spirometer (Chestac-65V unit; Chest, Tokyo, Japan) before sputum induction.

\section{Statistical analysis}

Data are presented as mean \pm SD or median (range). The MannWhitney U-test was used to analyse differences between two groups. Comparison of three groups was performed using analysis of variance and Fisher's protected least significant difference test or Chi-squared test. Correlations between data were analysed using Spearman's rank correlation test. A p-value of $<0.05$ was considered significant.

\section{RESULTS}

\section{Comparison of asthmatic patients and control subjects}

The characteristics and outcomes of the control subjects and two groups of patients with asthma are shown in table 1. Sex distribution, smoking status, FEV1 and BMI did not differ

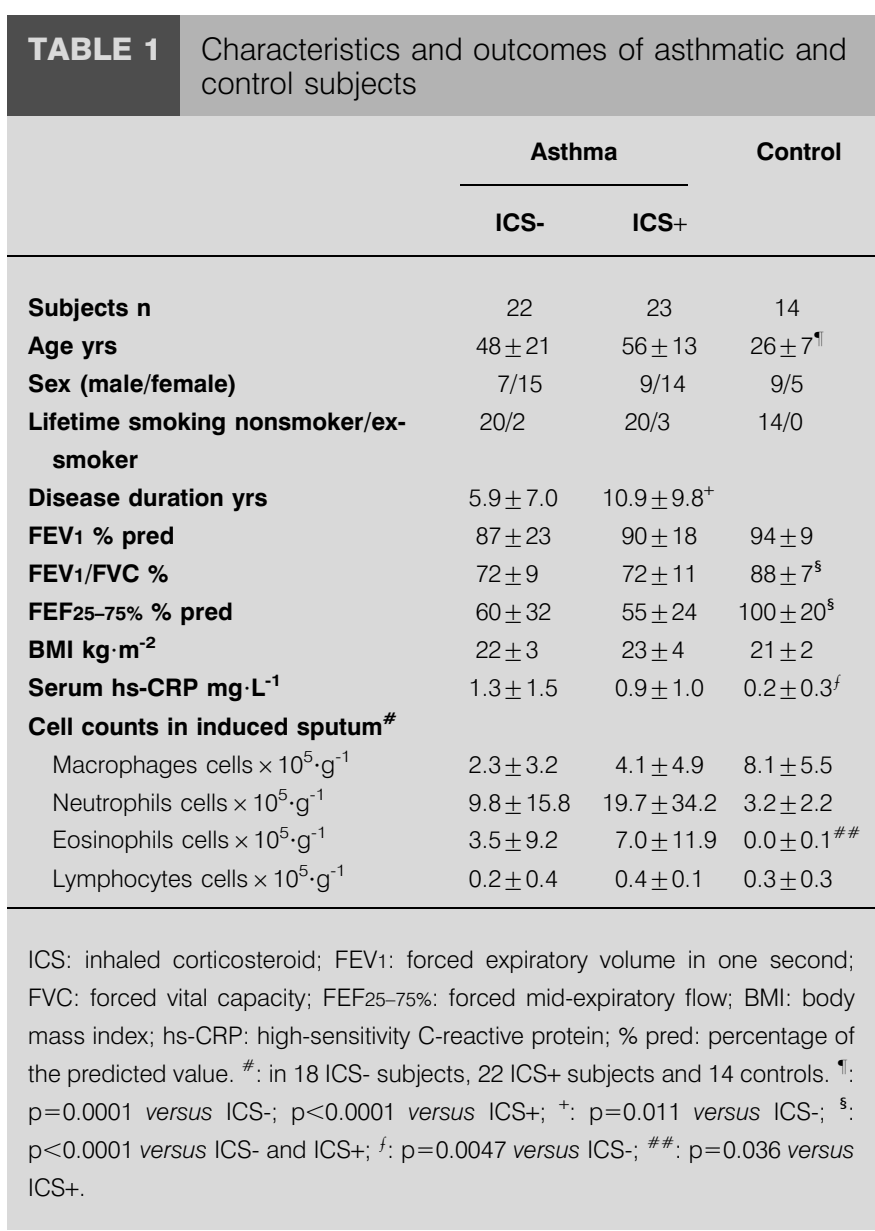

among the three groups. The healthy control group was younger than the two asthmatic groups. FEV1/FVC and FEF25$75 \%$ in the asthmatic groups were decreased compared with those in the control group. The number of sputum eosinophils was significantly increased in the ICS+ group compared to healthy controls, and disease duration in the ICS+ group was significantly longer than that in the ICS- group. Serum concentrations of hs-CRP were significantly increased in the ICS- group but not in the ICS+ group compared with healthy controls (fig. 1, table 1).

Relation between serum high-sensitivity C-reactive protein
levels and clinical or sputum indices in asthmatic patients In the ICS- group, serum hs-CRP levels correlated negatively with FEV1, FEV1/FVC and FEF25-75\%, and positively with numbers of sputum eosinophils (figs 2 and 3, table 2). There were marginal positive correlations between serum hs-CRP levels and numbers of sputum macrophages or neutrophils, but the correlations were nonsignificant. No correlation was found between serum hs-CRP levels and clinical indices (table 2).

In the ICS+ group, no significant correlation was found between serum hs-CRP levels and sputum or clinical indices (table 2). Atopic status did not affect hs-CRP levels in either the ICS+ group $\left(1.1 \pm 1.2 \mathrm{mg} \cdot \mathrm{L}^{-1}\right.$ in 15 atopic patients; $0.7 \pm 0.4 \mathrm{mg} \cdot \mathrm{L}^{-1}$ in eight nonatopic patients; $\mathrm{p}=0.84$ ) or the ICS- group $\left(1.7 \pm 1.7 \mathrm{mg} \cdot \mathrm{L}^{-1}\right.$ in 15 atopic patients; $0.6 \pm$ $0.3 \mathrm{mg} \cdot \mathrm{L}^{-1}$ in seven nonatopic patients; $\mathrm{p}=0.18$ ). 


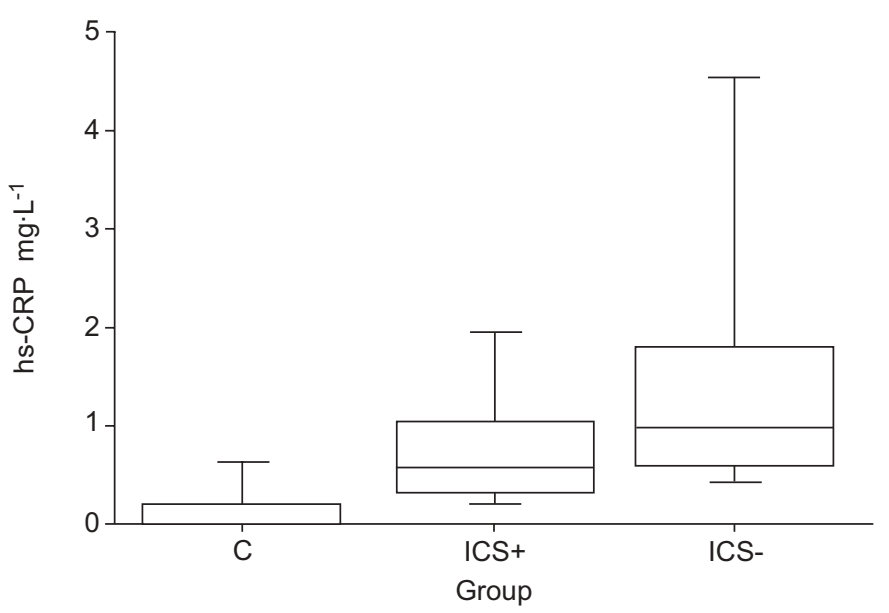

FIGURE 1. Serum high-sensitivity C-reactive protein (hs-CRP) levels in a healthy control group $(\mathrm{C} ; \mathrm{n}=14)$ and two asthmatic groups (inhaled corticosteroid $(I C S)+(n=23)$; ICS- $(n=22))$. Boxes represent median and interquartile range; whiskers represent the full range of values obtained. Levels of hs-CRP were significantly higher in patients with steroid-naive asthma than in healthy controls $(p=0.0047)$.

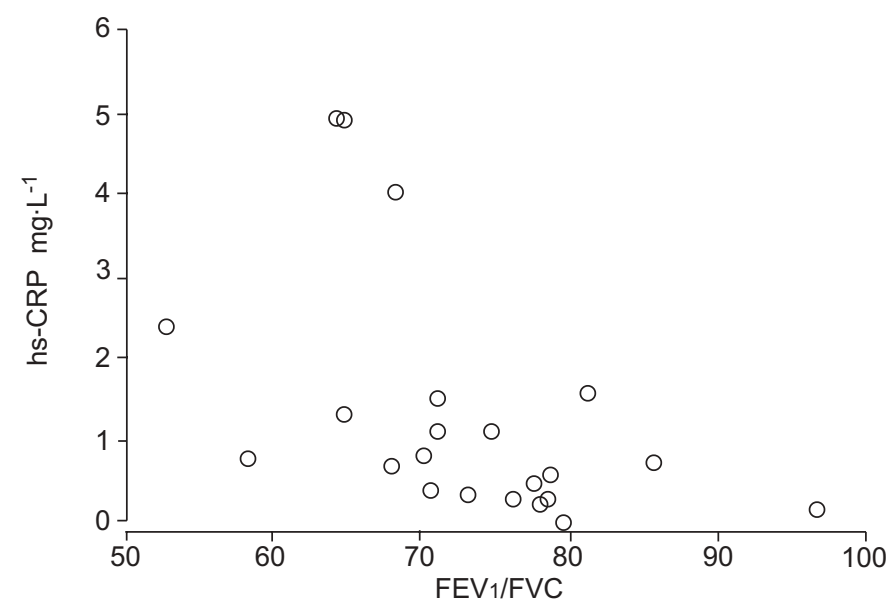

FIGURE 2. Relationship between serum high-sensitivity C-reactive protein (hs$\mathrm{CRP}$ ) levels and forced expiratory volume in one second (FEV1)/forced vital capacity $(F V C)$ in patients with steroid-naive asthma $(n=22, r=-0.63, p=0.004)$.

\section{DISCUSSION}

It has been shown, for the first time to the present authors' knowledge, that, in patients with steroid-naive asthma, serum levels of hs-CRP were increased compared with healthy controls, and correlated negatively with indices of pulmonary function and positively with numbers of sputum eosinophils. In steroid-inhaling patients with asthma, no significant correlations were found between serum hs-CRP levels and clinical and sputum indices.

In asthma, the importance of airway inflammation has been well established. Beside the airway inflammation, systemic inflammation may exist in asthma [12, 17, 18]. One study showed that serum amyloid A levels were significantly increased in 20 patients with asymptomatic asthma compared

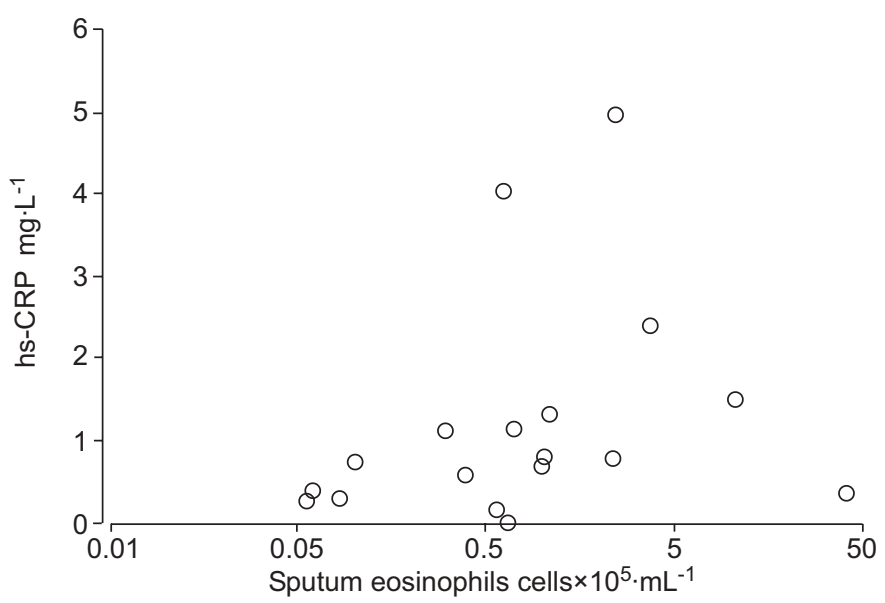

FIGURE 3. Relationship between serum high-sensitivity C-reactive protein (hsCRP) levels and numbers of sputum eosinophils in patients with steroid-naive asthma $(n=18, r=0.50, p=0.039)$.

$\begin{array}{llcccc}\text { TABLE } 2 & \text { Relationship between serum high-sensitivity } \\ \text { C-reactive protein (hs-CRP) levels and clinical or } \\ \text { sputum indices in patients with asthma }\end{array}$

with 20 healthy controls [17]. In another cross-sectional population-based study, levels of acute phase proteins, such as plasma fibrinogen and serum amyloid A, were positively associated with asthma prevalence [12]. Another recent multicentric epidemiological study showed that serum hs-CRP levels were increased in nonallergic asthma [11]. However, these studies did not further evaluate correlations between the degree of systemic inflammation and clinical indices in asthma. SÄVYKOSKI et al. [13] investigated the association 
between serum hs-CRP levels in asthmatic patients and Chlamydia pneumoniae infection. Their main result was that asthmatic patients with elevated levels of hs-CRP $\left(1.8 \mathrm{mg} \cdot \mathrm{L}^{-1}\right)$ exhibited higher levels of immunoglobulins A and G directed against Chlamydia pneumoniae than those with lower levels of hs-CRP. In addition, they demonstrated that serum hs-CRP levels were significantly higher in patients with mild-tomoderate asthma than in healthy controls. The difference in hs-CRP levels remained significant when the comparison was confined to patients with moderate asthma and healthy controls with a normal BMI $\left(<25 \mathrm{~kg} \cdot \mathrm{m}^{-2}\right)$ or nonsmokers. However, in their study, association of hs-CRP levels with airway obstruction or with airway inflammation was not addressed [13].

In the present study, patients with steroid-naive asthma showed increased serum hs-CRP levels compared with healthy controls. Moreover, serum hs-CRP levels correlated negatively with FEV1, FEV1/FVC and FEF25-75\%, positively with numbers of sputum eosinophils and marginally with numbers of macrophages and neutrophils. The present result confirmed the presence of systemic inflammation in asthma as shown previously $[12,17,18]$, and is the first to indicate an association of systemic inflammation with airway inflammation, as well as with decreased pulmonary function. Furthermore, in patients on ICS treatment, serum hs-CRP levels did not differ from those of healthy controls, and did not correlate with clinical or sputum indices. It is likely that the ICS, which has wellcharacterised anti-inflammatory properties, used in these patients might have reduced serum hs-CRP. Conversely, hsCRP could be a good marker of airway inflammation in steroid-naive patients with asthma.

Several factors other than the presence of asthma might affect serum levels of hs-CRP. Not only the presence of cardiovascular disease or diabetes mellitus but also obesity itself is associated with increased plasma hs-CRP levels, which may be due to adipocyte-derived interleukin-6 [19-21]. Smokers also show elevated hs-CRP levels, and smoking cessation leads to a reduction in hs-CRP level [2]. Ageing is another confounding factor of elevated hs-CRP levels [22]. The present patients were carefully selected to exclude these confounding factors, except for age, which was not adjusted for in the control group. However, the difference in hs-CRP levels between patients with steroid-naive asthma and healthy controls remained significant in age-adjusted comparisons (subjects aged $<40$ yrs) (data not shown). Atopic status could be another affecting factor as shown by a recent multicentric epidemiological study [11]. However, in the present study, atopic status did not affect hs-CRP levels in either steroid-naive or steroidinhaling patients.

In conclusion, it was found that, in steroid-naive patients, increased sputum eosinophil numbers and decreased pulmonary function were associated with higher serum highsensitivity C-reactive protein levels, which suggests that serum high-sensitivity C-reactive protein could be a surrogate marker, indirectly reflecting the degree of airway inflammation. However, further studies are required in order to better elucidate the clinical significance of the association of highsensitivity C-reactive protein and asthma, especially its responsiveness to treatment.

\section{REFERENCES}

1 Pepys MB, Baltz MC. Acute phase proteins with special reference to $\mathrm{C}$-reactive protein and related proteins (pentaxins) and serum amyloid A protein. Adv Immunol 1983; 34: 141-212.

2 Ridker PM. High-sensitivity C-reactive protein potential adjunct for global risk assessment in the primary prevention of cardiovascular disease. Circulation 2001; 103: 1813-1818.

3 Tracy RP. Inflammation in cardiovascular disease: cart, horse, or both? Circulation 1998; 97: 2000-2002.

4 Rifai N, Tracy RP, Ridker PM. Clinical efficacy of an automated high-sensitivity C-reactive protein assay. Clin Chem 1999; 45: 2136-2141.

5 Roberts WL, Sedrick R, Moulton L, Spencer A, Rifai N. Evaluation of four automated high-sensitivity C-reactive protein methods: implications for clinical and epidemiological applications. Clin Chem 2000; 46: 461-468.

6 Roberts WL, Moulton L, Law TC, et al. Evaluation of nine automated high sensitivity C-reactive protein methods: implications for clinical and epidemiological applications. Clin Chem 2001; 47: 418-425.

7 Pradhan AD, Manson JE, Rifai N, Buring JE, Ridker PM. Creactive protein, interleukin 6 , and risk of developing type 2 diabetes mellitus. JAMA 2001; 286: 327-334.

8 Ridker PM, Cushman M, Stampfer MJ, Tracy RP, Hennekens $\mathrm{CH}$. Inflammation, aspirin, and the risk of cardiovascular disease in apparently healthy men. $N$ Engl J Med 1997; 336: 973-979.

9 Ridker PM, Hennekens CH, Buring JE, Rifai N. C-reactive protein and other markers of inflammation in the prediction of cardiovascular disease in women. $N$ Engl J Med 2000; 342: 836-843.

10 Kony S, Zureik M, Driss F, Neukirch C, Leynaert B, Neukirch F. Association of bronchial hyperresponsiveness and lung function with C-reactive protein (CRP): a population based study. Thorax 2004; 59: 892-896.

11 Olafsdottir IS, Gislason T, Thjodleifsson $\mathrm{B}$, et al. $\mathrm{C}$ reactive protein levels are increased in non-allergic but not allergic asthma: a multicentre epidemiological study. Thorax 2005; 60: 451-454.

12 Jousilahti P, Salomaa V, Hakala K, Rasi V, Vahtera E, Palosuo T. The association of sensitive systemic inflammation markers with bronchial asthma. Ann Allergy Asthma Immunol 2002; 89: 381-385.

13 Sävykoski T, Harju T, Paldanius M, et al. Chlamydia pneumoniae infection and inflammation in adults with asthma. Respiration 2004; 71: 120-125.

14 American Thoracic Society. Standards for the diagnosis and care of patients with chronic obstructive pulmonary disease (COPD) and asthma. Am Rev Respir Dis 1987; 136: 225-243.

15 Pin I, Gibson PG, Kolendowicz R, et al. Use of induced sputum cell counts to investigate airway inflammation in asthma. Thorax 1992; 47: 25-29.

16 Takemura M, Niimi A, Minakuchi M, et al. Bronchial dilatation in asthma: relation to clinical and sputum indices. Chest 2004; 125: 1352-1358.

17 Büyüköztürk S, Gelincik AA, Genç S, et al. Acute phase reactants in allergic airway disease. Tohoku J Exp Med 2004; 204: 209-213. 
18 Enright P, Ward BJ, Tracy RP, Lasser EC. Asthma and its association with cardiovascular disease in the elderly. $J$ Asthma 1996; 33: 45-53.

19 Visser M, Bouter LM, McQuillen GM, Wener MH, Harris TB. Elevated C-reactive protein levels in overweight and obese adults. JAMA 1999; 282: 2131-2135.

20 Yudkin JS, Stehouwer CDA, Emeis JJ, Coppack SW. Creactive protein in healthy subjects: association with obesity, insulin resistance, and endothelial dysfunction: a potential role for cytokines originating from adipose tissue? Arterioscler Thromb Vasc Biol 1999; 19: 972-978.

21 Earl SF. Asthma, body mass index, and C-reactive protein among US adults. J Asthma 2003; 40: 733-739.

22 Nakamura H, Yamashita T. Predictive value of cardiovascular events by high sensitivity CRP. Nippon Rinsho 2002; 60: 916-921. 